\title{
A Cranio-Facial Dysmorphic Foetus; A New Syndrome?
}

\section{Prasanna LC}

Dr. LC Prasanna, MBBS, MS, Associate Professor, Center for Basic Sciences, KMC, Manipal University, Manipal-576104, India.

\section{Introduction}

Cranial Neural Crest (CNC) cells interact with and are consequently instructed by the pharyngeal endoderm, the branchial arch ectoderm, and the isthmic organizer at the midbrain- hindbrain boundary ${ }^{1}$ before giving rise to various types of tissues such as bone, cartilage, tooth, and cranial nerve ganglia ${ }^{1,2}$ in the craniofacial region.

\section{The Case}

We describe a rarest case of craniofacial malformation born with complete absence of facial skeleton and neck structures. Autopsy (Figure 1) revealed underdeveloped eyelid like structures were seen on both side with no orbital cavity and its contents. No congenital anomalies were noted in limbs. Scalp was thick and glistening membrane like sheath was found beneath it, which could represent the cranial vault. Interior of the cranial vault presents an ill defined cerebellar foliation like morphology in its posterior part with no visible cerebrum, dura and their venous sinuses, pituitary fossa and its gland, cranial nerves and foraminas in the cranial fossa. Babygram (Figure 2) showed cranial vault with complete absence of facial skeleton, hyoid bone, and thyroid cartilages. Vertebral column was normal in terms of number of vertebral bodies and their articulation.

\section{Discussion}

In mammals, both CNC-and mesoderm-derived cells contribute to the development of the skull. The skull consists of the neurocranium and viscerocranium. The neurocranium (skull vault and base) surrounds and protects the brain. Viscerocranium (the jaws and other pharyngeal arch derivatives) derived from the neural crest, forms the face. Couly and co-workers ${ }^{3}$ concluded
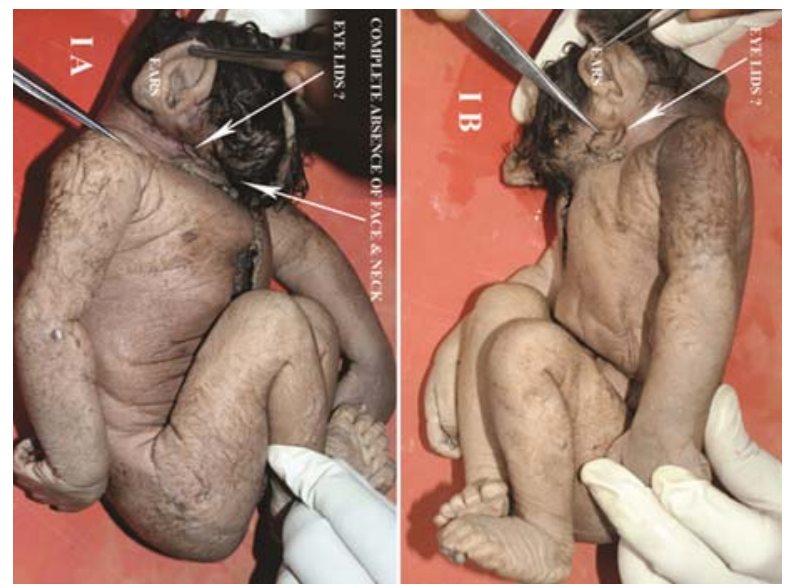

Fig 1

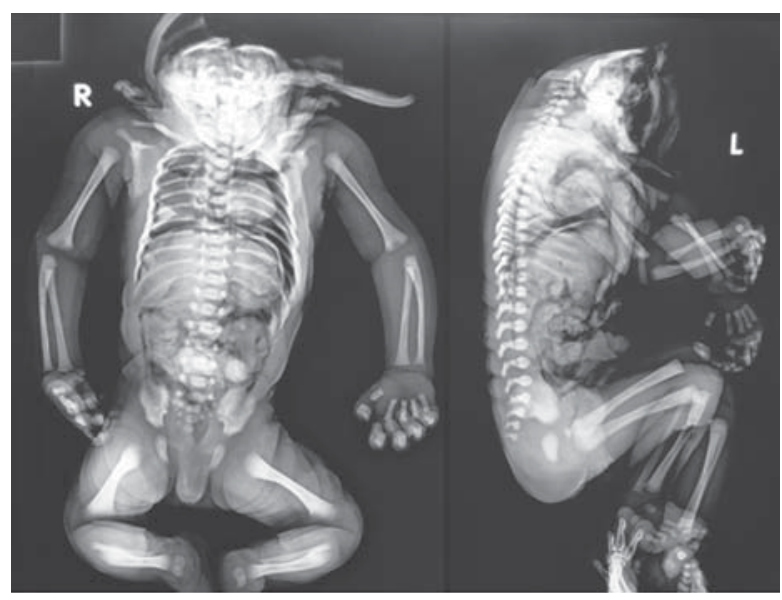

Fig 2

that the skull vault is entirely neural crest derived. It has been demonstrated by Jiang et al. ${ }^{4}$ that frontal bones are neural crest-derived and parietal bones are of mesoderm origin. The posterior part of the skull vault (supraoccipital and exoccipital bones) derived from the occipital somites. Later, as the cerebral vesicles expand beneath the frontal and parietal elements, crest-derived

\section{Address for correspondence \\ Dr. LC Prasanna \\ E-mail: anatomylcp@yahoo.com}

This work is licensed under a Creative Commons Attribution 3.0 License.

\section{How to cite this article?}

Prasanna LC. A Cranio-Facial Dysmorphic Foetus; A New Syndrome? J Nepal Paediatr Soc 2013;33(2):155-156. 
meningeal cells surrounding these parts of the brain are brought beneath the frontal and parietal osteogenic tissues to form the dura. The dura mater that underlies the frontal and parietal bones is also neural crest derived ${ }^{4}$.

It appears that the Neural crest cells display highly stereotyped migratory pattern, passing between neural and facial epithelia, and around paraxial mesoderm until they reach their locations in the pharyngeal arches and fronto-nasal process. Any inaccurate or interrupted migration lead to craniofacial malformation. Precisely how these disruptions influence cellular interaction and skeletal defects is not clear.

\section{References}

1. Trainor PA, Krumlauf R. Patterning the cranial neural crest: hindbrain segmentation and Hox gene plasticity. Nat Rev Neurosci 2000;1:144-165.

2. Noden DM, Trainor PA. Relations and interactions between cranial mesoderm and neural crest population. J Anat 2005;207:575-601.

3. Couly GF, Coltey PM, Le Douarin NM. The triple origin of skull in higher vertebrates: a study in quailchick chimeras. Development 1993;117:409-429.

4. Jiang $X$, Iseki S, Maxon RE, Sucov HM, MorrisKay GM. Tissue origins and interactions in the mammalian skull vault. Dev Biol 2002;241:106-110. 